\title{
Eksistensi Sanggah Kemulan Nganten dalam Upacara Perkawinan Masyarakat Desa Pedawa
}

\author{
Ni Ketut Purniati*, I Nyoman Suarsana, I Gusti Putu Sudiarna \\ Program Studi Antropologi, Fakultas Ilmu Budaya, Unud \\ Email: ketut.purniati97@,gmail.com \\ Gianyar, Bali, Indonesia \\ *Corresponding Author
}

\begin{abstract}
The community in Pedawa village, sub-district Banjar, districts Buleleng knows the term marriage they call with 'melaib' which is a local term which means to marry. Every man in Pedawa village who is married is obliged to make Sanggah Kemulan Nganten which is manifested in a series of wedding ceremonies. Sanggah Kemulan Nganten or also called sanggah tiing (a place of worship it made from bamboo) is a pelinggih (place of worship) symbol of the part of a new household from the individual. This study refers to understand and identify the process of the realization of Sanggah Kemulan Nganten in the marriage ceremony in the Pedawa village and, to find out and identify the meaning of Sanggah Kemulan Nganten in the life of the Pedawa village. The results of the study show that Sanggah Kemulan Nganten must be made by men. This refers to harmonize the household and block from the disease. Mandatory ceremony to establish Sanggah Kemulan Nganten is ngamputang lis. The meaning of religion from Sanggah Kemulan Nganten is to establish the belief in the existence of supernatural powers from Sanggah Kemulan Nganten. The meaning of solidarity from Sanggah Kemulan Nganten is participation and community support in the activities of establishing Sanggah Kemulan Nganten. The cultural meaning of Sanggah Kemulan Nganten is namely the pedawa village community,believes in local traditions or culture, which is in accordance with the mandate that has been passed down by generations of pedawa village ancestors.
\end{abstract}

Keywords : Sanggah Kemulan Nganten, Marriage Ceremony, Household.

\begin{abstract}
Abstrak
Masyarakat di Desa Pedawa, Kecamatan Banjar, Kabupaten Buleleng mengenal istilah perkawinan dengan sebutan melaib yang merupakan istilah lokal yang berarti kawin. Setiap laki-laki di Desa Pedawa yang sudah menikah wajib membuat Sanggah Kemulan Nganten yang diwujudkan dalam rangkaian upacara perkawinan. Sanggah Kemulan Nganten atau juga sering disebut dengan sanggah tiing (tempat pemujaan yang terbuat dari bambu) merupakan sebuah pelinggih (tempat pemujaan) simbol dari pembentukan rumah tangga baru dari individu tersebut. Penelitian ini bertujuan untuk mengetahui dan mengidentifikasi proses terwujudnya Sanggah Kemulan Nganten dalam upacara perkawinan masyarakat Desa Pedawa dan untuk mengetahui dan mengidentifikasi makna sanggah kemulan nganten dalam kehidupan masyarakat Desa Pedawa. Hasil penelitian menunjukan bahwa Sanggah Kemulan Nganten ini wajib dibuat. Hal ini bertujuan untuk keharmonisan rumah tangga dan terhindar dari penyakit. Upacara wajib untuk
\end{abstract}


mendirikan Sanggah Kemulan Nganten yaitu ngampuntang lis. Makna religi dari Sanggah Kemulan Nganten adalah memantapkan keyakinan adanya kekuatan supranatural dari Sanggah Kemulan Nganten. Makna solidaritas dari Sanggah Kemulan Nganten adalah partisispasi dan dukungan masyarakat dalam kegiatan mendirikan Sanggah Kemulan Nganten. Makna budaya Sanggah Kemulan Nganten yaitu masyarakat Desa Pedawa mempercayai tradisi ataupun budaya setempat yakni sesuai dengan amanat yang telah diwariskan secara turun-menurun oleh leluhur masyarakat Desa Pedawa.

Kata Kunci : Sanggah Kemulan Nganten, Upacara Perkawinan, Rumah Tangga.

\section{PENDAHULUAN}

Perkawinan termasuk salah satu bentuk ibadah. Tujuan perkawinan bukan saja untuk menyalurkan kebutuhan biologis, tetapi juga untuk menyambung keturunan dalam naungan rumah tangga yang penuh kedamaian dan cinta kasih (dalam Jurnal Sipayung, 2015: 1). Perkawinan dalam masyarakat Hindu di Bali dikenal dengan istilah seperti pawiwahan, nganten, makerab kambe, dll. Perkataan "kawin" dalam bahasa sehari-hari disebut dengan nganten dan makerab kambe, yang hakikatnya sama dengan perkawinan sebagaimana diatur dalam undang-undang perkawinan (Windia, 2009: 22-24). Berbeda dengan masyarakat di Desa Pedawa, Kecamatan Banjar, Kabupaten Buleleng perkawinan biasa disebut dengan melaib yang merupakan istilah lokal dari masyarakat setempat yang artinya kawin atau melangsungkan pernikahan. Perkawinan adat Bali dapat berlangsung jika kedua mempelai telah beragama Hindu (dalam Jurnal Dharmapatni, 2016: 2).

Setiap laki-laki di Desa Pedawa yang sudah menikah wajib membuat sanggah kemulan baru yang berbeda dengan sanggah kemulan sebelumnya yaitu disebut dengan sanggah kemulan nganten yang diwujudkan dalam rangkaian upacara perkawinan. Sanggah kemulan nganten atau juga sering disebut dengan sanggah tiing (tempat pemujaan yang terbuat dari bambu) merupakan sebuah pelinggih (tempat pemujaan) simbol dari pembentukan rumah tangga baru dari individu tersebut. Simbol- simbol dalam agama Hindu memiliki makna tersendiri, yang terkait dengan ajaran ketuhanan karena simbol tersebut merupakan salah satu bentuk ekspresi untuk mendekatkan diri kepada-Nya (dalam Jurnal Fauziana dkk, 2017:245).

Sanggah kemulan merupakan tempat pemujaan Sanghyang Tri Atma (paratma, atma dan siwatma), Sanghyang Tri Murthi, Bhatara Guru, Sanghyang Guru Reka dan roh leluhur yang telah disucikan (Sanghyang Pitara) (dalam Jurnal Laksmi, 2014 :6). Terdapat keunikan dari sanggah kemulan nganten di Desa Pedawa yaitu menurut kepercayaan masyarakat di Desa Pedawa ada pengertian dari purusa dan predana harus saling mengikuti dan tidak dapat dipisahkan. Setiap laki-laki yang menikah dengan perempuan dari dalam maupun luar Desa Pedawa harus mendirikan sanggah kemulan nganten dan juga harus ikut ngelinggihang (menempatkan) sung-sungan bhatara dari pihak istri dalam sanggah kemulan ngantennya tersebut.

Dari pihak laki-laki akan nunas (meminta) yos (kawitan lokal) yang sesuai dengan sung-sungan bhatara dari mempelai perempuan ke anak lingsir (orang tertua dalam yos pihak laki-laki tersebut) atau nunas ke balian (orang pintar) Desa untuk kemudian bisa ngelinggihang (menempatkan) bersama di sanggah kemulan nganten tersebut. Secara simbolis sung-sungan bhatara dari pihak laki-laki dan sung-sungan bhatara dari pihak istri menikah di sanggah kemulan nganten tersebut dan 
kemudian bisa memujanya bersamasama.

Sanggah kemulan nganten ini sangat sederhana semua bahan masih terbuat dari bambu walaupun zaman sudah berkembang begitu pesat namun keberadaan Sanggah Kemulan Nganten ini masih tetap eksis. Eksistensi merupakan keberadaan wujud yang tampak (dalam Jurnal Maritfa Nika dan Mohammad Mukti 2013: 13). Berdasarkan hal tersebut dan pemaparan yang telah disampaikan sebelumnya, maka fenomena ini menarik untuk dikaji dalam sebuah penelitian yang berjudul, "Eksistensi Sanggah Kemulan Nganten Dalam Upacara Perkawinan Masyarakat Desa Pedawa". Berdasarkan uraian latar belakang di atas, maka permasalahan yang dapat dirumuskan sebagai berikut: Bagaimana proses terwujudnya sanggah kemulan nganten dalam upacara perkawinan masyarakat Desa Pedawa, Kecamatan Banjar, Kabupaten Buleleng?. Apa makna sanggah kemulan nganten dalam kehidupan masyarakat Desa Pedawa, Kecamatan Banjar, Kabupaten Buleleng?.

Adapun tujuan yang dicapai dalam penelitian ini adalah sebagai berikut: Untuk mengetahui dan mengidentifikasi proses terwujudnya sanggah kemulan nganten dalam upacara perkawinan masyarakat Desa Pedawa. Untuk mengetahui dan mengidentifikasi makna sanggah kemulan nganten dalam kehidupan masyarakat Desa Pedawa.

\section{METODE}

Metode yang digunakan dalam penelitian ini yaitu metode penelitian kualitatif. Heriyawati (2016:72) menyatakan bahwa penelitian kualitatif adalah penelitian yang tidak menggunakan model matematika, statistik, atau komputer. Penelitian ini dilakukan di Desa Pedawa, Kecamatan Banjar, Kabupaten Buleleng. Teknik pengumpulan data dilakukan melalui teknik penentuan informan, observasi yaitu dalam penelitian ini pengamatan dilakukan secara keseluruhan setting penelitian (grand tour observation), selanjutnya mengidentifikasi dan mengkategorisasi lebih terfokus (minitour observation) pada fenomena sosial budaya masyarakat (Spradley, 1980: 27). Wawancara yang dilakukan adalah wawancara mendalam (in-dept interview) dilakukan terhadap informan yang dipilih untuk menghasilkan informan yang mempunyai kedalaman makna (Spradley, 1979: 14). Kepustakaan dan analisis data juga dilakukan untuk mendapatkan informasi yang mendalam tentang fenomena sosial budaya masyarakat bersangkutan.

\section{HASIL DAN PEMBAHASAN}

\section{Proses Terwujudnya Sanggah Kemulan Nganten dalam Upacara Perkawinan Masyarakat Desa Pedawa}
a. Perkawinan Masyarakat Desa Pedawa

Hukum adat di Bali mengenal dua cara melangsungkan perkawinan yaitu kawin dengan cara memadik (meminang) dan kawin dengan cara ngerorod (lari bersama) (dalam Jurnal Firmansyah, 2017: 2-3). Berbeda dengan masyarakat di Desa Pedawa, Kecamatan Banjar, Kabupaten Buleleng perkawinan biasa disebut dengan melaib yang merupakan istilah lokal dari masyarakat setempat yang artinya kawin atau melangsungkan pernikahan. jenis-jenis perkawinan di Desa Pedawa ada enam yaitu melaib ngemaling, melaib ngidih, melaib nangken, melaib negteg, melaib mebase tegeh, melaib ngerorod. Sejalan dengan sistem patrilineal yang dianut masyarakat Bali pada umumnya, perkawinan yang biasa digunakan adalah perkawinan biasa. Perkawinan biasa adalah perkawinan antara seorang laki-laki dan perempuan Hindu di Bali yang diadakan 
di rumah keluarga besar suami (dalam Jurnal Kusmirayani, 2013: 2). Sama halnya dengan masyarakat di Desa Pedawa juga menganut sistem perkawinan patrilineal.

Sebuah jurnal hasil penelitian dari Dewa Pramana (2017) yang berjudul "Tradisi Naur Kelaci dalam Upacara Perkawinan di Desa Subaya, Kecamatan Kintamani, Kabupaten Bangli” memaparkan tentang tradisi yang mengikat tentang adat perkawinan penduduk Desa Subaya yaitu "tradisi Naur Kelaci". Naur Kelaci merupakan salah satu rangkian terakhir dari proses upacara perkawinan yang diperuntukan bagi warga masyarakatnya yang telah menikah. Berbeda dengan Setiap laki-laki di Desa Pedawa dimana setiap laki-laki yang sudah menikah wajib membuat sanggah kemulan nganten yang diwujudkan dalam rangkaian upacara perkawinan.

\section{b. Asal-Usul Sanggah kemulan Nganten}

Sampai saat ini belum ditemukan adanya prasasti atau lontar-lontar mengenai sejarah ataupun asal-usul Sanggah Kemulan Nganten. Masyarakat Desa Pedawa tidak memiliki catatan mengenai sejarah dari asal usul keberadaan Sanggah Kemulan Nganten di desa setempat. Namun ada cerita mengenai cikal-bakal sampai adanya Sanggah Kemulan Nganten di Desa Pedawa. Menurut keterangan Bapak Wayan Sukrata asal-usul Sanggah Kemulan Nganten yaitu berawal dari seseorang mengalami kesakitan, pada saat merasa kesakitan seseorang tersebut akan nunas (meminta) petunjuk ke Balian atau orang pintar. Setelah dilihat bahwa seseorang tersebut belum membangun Sanggah Kemulan Nganten, makanya oleh karena itu secara terusmenerus mengalami kesakitan. Setelah membangun Sanggah kemulan Nganten kesakitan itupun hilang dan hidup keluarga tersebut menjadi harmonis. c. Proses Mendirikan Sanggah
Kemulan Nganten
Prosesi dalam upacara perkawinan memiliki tata cara yang bervariasi sesuai tradisi dalam masyarakat, dan setiap kebudayaan memiliki cara untuk memaknai perkawinan itu sendiri (dalam Jurnal Dade, 2012: 1). Pada masyarakat Desa Pedawa setelah setiap laki-laki melangsungkan perkawinan maka diwajibkan untuk mendirikan Sanggah Kemulan Nganten. Pembuatan Sanggah Kemulan Nganten ini memiliki beberapa rangkaian kegiatan. Adapun proses pertama pembuatan Sanggah Kemulan Nganten yakni warga yang akan mendirikan Sanggah Kemulan Nganten terlebih dahulu menyampaikan pemberitahuan kepada Balian Desa sekaligus untuk meminta pertimbangan mengenai rong (ruang) apa saja yang akan dilinggihkan (ditempatkan) pada Sanggah Kemulan Nganten.

Selanjutnya akan dilakukan penentuan hari baik untuk melaksanakan upacara dalam pembuatan Sanggah Kemulan Nganten. Biasanya hari purnama yang dipilih dan dianggap baik adalah pada saat purama kapat (keempat) dan punama kedasa (kesepuluh). selanjutnya keluarga akan mulai mencari bahan untuk mendirikan Sanggah Kemulan Nganten. Ketika dewasa ayu (hari baik) itu telah tiba dan Sanggah Kemulan Nganten sudah berdiri maka akan dilaksanakan upacara untuk Sanggah Kemulan Nganten yakni bernama Ngamputang Lis.

Proses pertama yang dilakukan pada saat upacara Ngamputang Lis yaitu nunas pengrapuhan (nunas tirta)/ (mencari air suci yang digunakan untuk upacara ngamputang lis). semua tirta (air suci) ini akan digunakan untuk kelengakapan upacara Ngamputang Lis. Pada saat semua tirta sudah terkumpul maka selanjutnya dilakukan proses Pemanyuawang terlebih dahulu. 
Pemanyuawang adalah proses awal pada saat baru pertama kali mendirikan Sanggah Kemulan Nganten tujuan pemanyuawang ini untuk membersihkan Sanggah Kemulan Nganten terlebih dahulu untuk selanjutnya baru diperbolehkan ngunggahang banten (diisikan sarana) pada setiap rong Sanggah Kemulan Nganten.

Jika proses Pemanyuawang sudah selesai baru selanjutnya mulai melaksanakan upacara ngamputang lis. Upacara Ngamputang Lis dilaksanakan dengan mantra sesuai dengan banten (sarana) ngamputang lis yang muput (memimpin) adalah Balian Desa. Ketika upacara ngamputang lis sudah selesai maka selanjutnya dilaksanakan proses Ngerapuh yaitu tirta (air suci) yang sudah dikumpulkan tersebut dipercikkan ke Sanggah Kemulan Nganten. kemudian keluarga yang mendirikan Sanggah Kemulan Nganten tersebut sembahyang untuk meminta keharmonisan pada keluarga dan dijauhkan dari kesakitan.

Pada saat selesai sembahyang maka sudah selesai rangkaian upacara Ngamputang Lis tetapi untuk semua banten-banten (sarana) yang digunakan akan didiamkan terlebih dahulu atau istilah lokal dalam masyarakat Pedawa yaitu Ngayengan. Proses Ngayengan ini berlangsung selama dupa yang diisikan di Sanggah Kemulan Nganten tersebut habis atau padam, Ketika semua rangkaian sudah dilaksanakan maka Sanggah Kemulan Nganten tersebut sudah dianggap sakral.

\section{d. Tata Letak Sanggah Kemulan Nganten}

Masyarakat Desa Pedawa hanya mempercayai konsep Ulu-Teben. Ulu berarti lebih tinggi, biasanya yang ditempatkan untuk tempat suci atau sakral. Teben berarti lebih rendah, biasanya ditempatkan untuk membuat kandang, jineng, tempat kayu api dan kamar mandi. Pada saat akan mendirikan Sanggah Kemulan Nganten biasanya tempat yang digunakan yaitu bagian Ulu karena dianggap lebih suci. Biasanya letak Sanggah Kemulan Nganten berada di bagian belakang rumah karena posisinya lebih tinggi (Ulu) dari bagian rumah lainnya.

e. Peran Balian Desa dalam Pembuatan Sanggah Kemulan Nganten

Balian Desa merupakan seseorang yang memiliki wewenang sebagai pemuput (pemimpin) dalam segala upacara dari adat. Maka dari itu, Balian Desa sangat berperan dalam upacara mendirikan Sanggah Kemulan Nganten karena Balian Desa yang memimpin dan menentukan banten-banten (sarana) yang diperlukan pada saat upacara Ngamputang Lis dan beliau juga yang memberikan pertimbangan pada saat ada yang membuat Sanggah Kemulan Nganten dengan pertimbangannya yaitu seperti yos (kawitan lokal) mana yang sesuai dengan sung-sungan bhatara dari pihak istri dan berapa jumlah rong (ruang) yang sesuai dengan kepercayaan individu tersebut.

f. Upakara (banten) dalam Pembuatan Sanggah Kemulan Nganten

Banten daksina baas pipis canang meraka ini merupakan salah satu banten yang wajib ada pada saat upacara mendirikan Sanggah Kemulan Nganten di Desa Pedawa karena banten ini menyimbolkan pura sad kahyangan karena kita harus bersyukur kepada Ida Sang Hyang Widhi Wasa yang telah memberikan kita kehidupan.

Selain menggunakan banten daksina baas pipis canang meraka, pada saat upacara mendirikan Sanggah Kemulan Nganten juga menggunakan banten pespesan yang terdiri dari daun punggel (pucuk daun pisang) yang berisikan nasi mecekolan memakai cetakan dari tempurung kelapa yang kecil selanjutnya ditumpuk lagi dengan pucuk daun pisang yang berisikan pespesan terdiri dari 
garam, kulit kidang, pangi, kacang, gerang yang dicampur parutan kelapa, daun labu dan tengah-tengahnya berisikan telur selanjutnya ditumpuk lagi dengan pucuk daun pisang yang berisikan jajan uli putih dan jaje abug (jajan uli merah), tape isi 2, tebu, biu (pisang) dan jaje gorengan. Banten pespesan ini juga wajib ada pada saat upacara mendirikan Sanggah Kemulan Nganten. Terdapat juga banten pelawah yang berisikan base lunggahang dan sekar.

Masyarakat Desa Pedawa juga mengenal banten pengundang. banten pengundang ini merupakan banten untuk Balian Desa. agar diketahui oleh Balian Desa bahwa keluarga tersebut membuat upacara keagamaan. Ini hanya sebagian banten karena Banten di Desa Pedawa tidak boleh di ucapkan sembarangan jika tidak sedang membuat banten tersebut, karena dengan mengucapkan sarana banten sama artinya dengan mengucapkan mantra (doa).

\section{Makna Sanggah Kemulan Nganten dalam Kehidupan Masyarakat Desa Pedawa}

\section{a. Makna Religi}

Sebuah jurnal hasil penelitian dari Riski Dwi Purwandari dkk (2014) memaparkan tentang simbol dan makna pernikahan adat Jawa yaitu seperti upacara siraman maknanya yaitu untuk membersihkan diri dari hal-hal yang kotor dan negatif. Pada Sanggah Kemulan Nganten di Desa Pedawa ini yang diwujudkan dalam rangkaian upacara perkawinan mengandung makna religi sebagai berikut :

1). Sebagai pelaksanaan rutin yang wajib digelar setiap ada laki-laki di Desa Pedawa yang menikah, ini merupakan kewajiban dalam berwarga Desa dan berupacara Agama Hindu menurut kepercayaan masyarakat setempat yang mempercayai adanya kekuatan supranatural dari Sanggah Kemulan Nganten tersebut sehingga setiap laki- laki di Desa Pedawa mau mendirikannya. Hartawan dkk (2017: 155) menyatakan bahwa sistem religi berwujudkan aktivitas dan tindakan manusia dalam melaksanakan kebaktiannya kepada Tuhan, para dewa, roh nenek moyang, atau makhluk halus lain, dan dalam usahanya untuk berkomunikasi dengan Tuhan dan penghuni gaib lainnya.

2). Pelaksanaan mendirikan Sanggah Kemulan Nganten bagi setiap laki-laki di Desa Pedawa yang sudah menikah untuk memantapkan keyakinan masyarakat setempat, bahwa jika sudah mendirikan Sanggah Kemulan Nganten ini maka dapat menghantarkan setiap pasangan ini untuk mencapai tujuan keselamatan, kesejahteraan, serta kemakmuran, keharmonisan, dan kebahagiaan lahirbatin pada rumah tangga mereka.

\section{b. Makna Solidaritas}

Makna solidaritas yang terkandung dalam Sanggah kemulan Nganten yaitu terlihat pada saat pembuatan bantenbanten (sarana) ataupun keperluan untuk penyelenggaraan upacara mendirikan Sanggah Kemulan Nganten, masyarakat turut membantu keluarga tersebut agar upacara mendirikan Sanggah kemulan Nganten berjalan dengan lancar dan sarana yang digunakan lengkap tanpa kekurangan apapun. Saling tolong menolong untuk mendirikan Sanggah Kemulan Nganten ini biasanya dilakukan dengan rela dan ikhlas, karena masyarakat yang turut dalam kegiatan ini juga merasakan suasana gembira, dapat berbincang-bincang satu dengan yang lainnya, dan dapat mempererat solidaritas masyarakat setempat. Sistem kekerabatan dan perkawinan sangat menentukan keberlangsungan tatanan adat-istiadat serta struktur sosialnya secara harmonis (dalam Jurnal Manalu, 2013:1).

Pihak laki-laki maupun keluarga dari pihak istri memiliki peranan terhadap kegiatan mendirikan Sanggah Kemulan Nganten serta dapat memantapkan 
solidaritas. Dalam upacara mendirikan sanggah kemulan nganten terlihat makna solidaritas yang masih sangat kental, keluarga maupun masyarakat saling tolong-menolong pada saat proses mendirikan Sanggah Kemulan Nganten ini. Masyarakat juga biasanya membantu pada saat pembuatan banten karena upacara mendirikan Sanggah Kemulan Nganten ini memerlukan banten yang lumayan banyak dan masyarakat juga membantu pada saat akan mendirikan Sanggah kemulan Nganten.

\section{c. Makna Budaya}

Makna budaya pada Sanggah Kemulan Nganten yaitu masyarakat Desa Pedawa masih mempercayai Sanggah Kemulan Nganten karena kepercayaan masyarakat berkaitan dengan tradisi ataupun budaya setempat yakni sesuai dengan amanat yang telah diwariskan secara turun-menurun oleh leluhur masyarakat Desa Pedawa. Jadi sampai saat ini masyarakat Desa Pedawa masih melestarikan Sanggah Kemulan Nganten dengan tetap mau mendirikannya walaupun belum ada aturan pasti tentang kewajiban untuk mendirikan Sanggah Kemulan Nganten namun dalam tataran niskala masyarakat Desa Pedawa mempercayai bahwa mendirikan Sanggah Kemulan Nganten itu wajib.

\section{SIMPULAN}

Sanggah Kemulan Nganten atau juga sering disebut dengan Sanggah Tiing (tempat pemujaan yang terbuat dari bambu) merupakan sebuah Pelinggih (tempat pemujaan) simbol dari pembentukan rumah tangga baru dari individu tersebut. Sanggah kemulan nganten ini wajib dibuat oleh laki-laki di Desa Pedawa yang sudah menikah. Hal ini bertujuan untuk keharmonisan rumah tangga dan agar terhindar dari penyakit. Makna Sanggah Kemulan Nganten bagi masyarakat Pedawa meliputi makna religi, makna solidaritas, dan makna budaya.

\section{REFERENSI}

Firmansyah dkk. 2017. "Kedudukan Anak Dalam Perkawinan Adat Ngerorod (Kawin Lari) di Desa Padang Sambian Kaja, Kecamatan Denpasar Barat, Denpasar”. Semarang: Jurnal Universitas Diponegoro Volume 6 No. 2: 2-3.

Heriyawati, Yanti. 2016. Seni Pertunjukan Dan Ritual. Yogyakarta: ombak.

Nika, Maritfa, dan Mohammad Mukti. 2013. Jurnal Kajian Eksistensi Pasar Tradisional Kota Surakarta. Solo: ejurnal Undip Volume 2 No. 2.

Pramana, Dewa. 2017. Tradisi Naur Kelaci dalam Upacara Perkawinan di Desa Subaya, Kecamatan Kintamani, Kabupaten Bangli. Program S1 Antropologi. Universitas Udayana Volume 23 No.1.

Riski dkk. 2014. "Simbol Dan Makna Pernikahan Ritual Pernikahan Adat Jawa Di Desa Sukomanah Kecamatan Purwodadi Kabupaten Purworejo". Yogyakarta. Jurnal Universitas Negeri Yogyakarta Volume 3 No. 7.

Spradley, J.P. 1979. The Ethnographic Interview. New York: Reinhart \& Winston.

Spradley, J.P. 1980. The Participation Observation. New York: Reinhart \& Winston. 
Windia, Wayan, P. dkk. 2009. Perkawinan Pada Gelahang di Bali. Denpasar: Udayana Press.

Dade, Yacobus Tenabolo. 2012. Dinamika Belis dalam Adat Perkawinan Masyarakat Rote Ba'a di Kelurahan Mokdale Kecamatan Lobalain Kabupaten Rote Ndao. Program S1 Antropologi. Jurnal Universitas Udayana Volume 1 No.1.

Kusmirayani, Luh Ayu. 2013. Perkawinan Padagelahang di Bali Perspektif Antropologi. Program S1 Antropologi. Jurnal Universitas Udayana Volume 3 No.1.

Laksmi, Ni Luh Gede Eni. 2014. Tutur Ardhasmara Analisis Struktur dan Semiotika. Program S1 Sastra Jawa Kuno. Jurnal Universitas Udayana Volume 7 No.1.

Dharmapatni, Desak Putu Diah. 2016. Adaptasi Wanita Islam Terhadap Keluarga Suami Studi Kasus Perkawinan Amalgamasi Wanita Islam dan Pria Hindu di Bali. EJurnal Humanis Unud Volume 15 No.1.

Hartawan Dana Putra dkk. 2017. Makna Ritual Nyepeg Sampi dalam Upacara Usaba Kawulu di Desa Adat Asak Kabupaten Karangasem. Jurnal Humanis, Fakultas Ilmu Budaya Unud Volume 21 No.1.

Fauziana Rahmat dkk. 2017.
Representasi Simbol
Gonggang diti
Gunung Raung Desa Agung
Kecamatan Tegallalang, Gianyar.
Jurnal Humanis, Fakultas Ilmu
Budaya Unud Volume 21 No. 1.

Manalu, Mely Tri Santy Br. 2013. Kebertahanan Perkawinan Ideal Menurut Suku Batak Karo di Kelurahan Kwala Bekala Padang Bulan Medan (Suatu Tinjauan Antropologi). Jurnal Humanis Unud Volume 2 No. 1.

Sipayung, Frans Kurnia. 2015. Dinamika Sistem Upacara Perkawinan Batak Simalungun di Kabupaten Simalungun, Sumatra Utara Tahun 1950-2010. Jurnal Humanis Unud Volume 11 No. 1. 